\title{
Microarchitectonic of Decellularized Bovine Pericardium Matrix
}

\author{
Nataliia V. Shchotkina ${ }^{1,2,3}$, Anatoliy A. Sokol ${ }^{1}$, Glib I. Yemets ${ }^{1}$, Oleksandr Yu. Galkin'2, Liudmyla V. \\ Dolinchuk $^{2}$, Arkadii A. Dovghaliuk ${ }^{1}$, Iryna M. Skorokhod ${ }^{3}$, Olena V. Shepeleva ${ }^{2}$, Nadiia M. Rudenko', \\ Iliia M. Yemets ${ }^{1}$ \\ ${ }^{1}$ Center for Pediatric Cardiology and Cardio Surgery, 24, Yurii Ilyenko street, Kyiv, Ukraine, ${ }^{2}$ National Technical \\ University of Ukraine "Igor Sikorsky Kyiv Polytechnic Institute”, 37, Prosp. Peremohy, Kyiv, Ukraine, ${ }^{3}$ XPand \\ LLC, 40D, Kvitky Cisyk street, Kyiv, Ukraine \\ nataliia.shchotkina@xpandmed.com.ua
}

\begin{abstract}
The use of xenotissue for the needs of regenerative and cardiac medicine is a promising area of tissue engineering. The decellularization process provides complete purification of the elastin-collagen matrix of the bovine pericardium from cells and their components. The use of high concentrations of sodium dodecyl sulfate and glutaraldehyde can lead to a damage of the matrix architectonics. Therefore, the purpose of this study was to study the microarchitectonics of the decellularized matrix using a low concentration of sodium dodecyl sulfate $(0.1 \%$ solution) and avoiding glutaraldehyde. Further stabilization and fixation of the matrix was carried out using $10 \mathrm{mM} 1$ Ethyl-3 (3-dimethylaminopropyl) carbodiimide hydrochloride and $10 \mathrm{mM}$ N-Hydroxysuccinimide. The effect of decellularization was assessed by staining the samples with hematoxylin-eosin and by scanning electron microscopy. The research results confirmed the absence of structural changes in the collagen-elastin fibers of the matrix. Thus, the efficiency of using the proposed technology for obtaining a decellularized matrix based on the bovine pericardium was confirmed.
\end{abstract}

Keywords: tissue engineering, cardiac implant

\section{Introduction}

Tissue engineering has been recognized as a promising alternative to donor tissues, which often are in short supply. The concept of extracellular matrix (ECM) isolation of cells from native tissues and genetic material in order to produce a natural scaffold is a main goal of the decellularization. Clinically, ECM of biological tissues has been used in manufacturing heart valve prostheses, small-diameter vascular grafts, and biological patches [1-3]. The scientific literature confirms the effective use of ionic detergent SDS for decellularization process. The matrix is purified via solubilization of cytoplasmic and nuclear membranes, denaturation of proteins and removal of nuclear residues [4, 5]. However, these ECM have to be fixed with a crosslinking agent and subsequently sterilized before the implantation to humans [6]. Crosslinking can enhance the mechanical strength and reduce the immunogenicity of implanted grafts. In this study, we evaluated the effects of decellularized agent and cross-linking on the matrix microstructure.

\section{Materials and Methods}

\subsection{The procedure for tissue obtaining.}

The material for the study was the bovine pericardium (BP). The pericardial sac was extracted from outbred 12-18 month old bulls after slaughter at the "Antonivskii Meatplant Ltd.". The research was performed in accordance with the General Ethical Principles of Animal Experiments (Strasbourg, France, 1985) and Law of Ukraine No. 3447 - IV On Protection of Animals from Cruel Treatment (2006, edited in 2009). The biomaterial was transported to the laboratory during one hour in sterile Hanks solution in a container on ice. Pericardial sacs were dissected and non-fibrous components were removed. The tissue samples were cut in $40 \times 40 \mathrm{~mm}$. Samples were placed in distilled water in a volume of $1000 \mathrm{ml}$ and stirred continuously $(70 \mathrm{rpm})$ for 3 hours at $4{ }^{\circ} \mathrm{C}$.

\subsection{Glutaraldehyde-free decellularization of the bovine pericardium.}


BP samples were decellularized as follows: (1) osmotic shock was caused by placing samples into sterile distilled water ( 5 pieces per $500 \mathrm{ml}$ of the solution) at $4^{\circ} \mathrm{C}$ for 72 hours $(200 \mathrm{rpm})$. Water was changed every $6-8$ hours; (2) decellularization with $100 \mathrm{ml}$ of $0.1 \%$ solution of SDS (Sigma-Aldrich, USA) with constant shaking (200 rpm) for 35 days at $4{ }^{\circ} \mathrm{C}$; (3) washed with sterile $\mathrm{NaCl}$ solution for 7 days at $4{ }^{\circ} \mathrm{C}$ with constant shaking at $200 \mathrm{rpm}$; (4) stabilization and fixation in a solution of $70 \%$ ethanol for $24 \mathrm{~h}$ at t $4{ }^{\circ} \mathrm{C}$ with constant shaking at $200 \mathrm{rpm}$; (5) washed with sterile NaCl solution for 24 $\mathrm{h}$ at $4{ }^{\circ} \mathrm{C}$ with constant shaking at $200 \mathrm{rpm}$; (6) cross-linking method - EDC/NHS solution - MES (10 mM 1-Ethyl-3- (3-

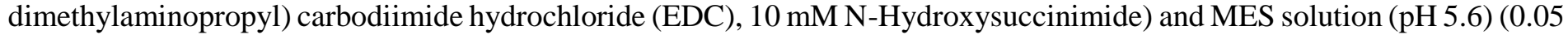
M 2-morpholinoethane sulfonic acid); (7) washed with sterile $\mathrm{NaCl}$ solution for $24 \mathrm{~h}$ at $4{ }^{\circ} \mathrm{C}$ with constant shaking at 200 rpm. Non decellularized pericardial tissues were chosen as control samples.

\subsection{Histological analysis.}

Segments of non decellularized $(n=10)$ and decellularized $(n=10)$ pericardial tissues were fixed in $10 \%$ neutral buffered formalin (Sigma-Aldrich, USA) for $1 \mathrm{~h}$, embedded in paraffin, cut into 5 - $\mu \mathrm{m}$ sections and stained with hematoxylin $\&$ eosin (H\&E, Sigma Aldrich, USA). The stained samples were examined with Olympus BX 51 light microscope (Tokyo, Japan).

\subsection{Scanning electron microscopy (SEM).}

The samples of decellularized pericardium were dried by lyophilization at a vacuum depth of 30-50 $\mathrm{Pa}$ and a temperature of $-50^{\circ} \mathrm{C}$. (JFC-1100, Jeol, Tokyo, Japan). In order to eliminate the accumulation of surface charge during scanning with an electron beam in a microscope column, a thin layer of gold was applied to the dried samples by cathodic sputtering (JFC1100, Jeol, Tokyo, Japan). The preparations were investigated in SEM JSM 6060 LA (Jeol, Tokyo, Japan) in the secondary electron mode at an electron acceleration voltage of $30 \mathrm{kV}$.

\subsection{Statistical analysis.}

The analysis of the research results was carried out using biostatistical methods [7]. For quantitative values, the normality distribution was analyzed using the Shapiro-Wilk test. The mean value $(\mathrm{M})$ and standard deviation $( \pm \mathrm{SD})$ were calculated. To estimate the mean value, its $95 \%$ confidence interval (95\% CI) was calculated. For qualitative values, the frequency (\%) and, if necessary, 95\% CI were calculated. When comparing quantitative parameters in more than two groups, one-way ANOVA was used [7], posteriori comparisons were carried out using Scheffe Test (The distribution law did not differ from normal). To compare qualitative parameters, the chi-square test was used, posteriori comparisons for more than two groups were carried out taking into account the Bonferroni correction [7-9]. In the analysis, the criteria for a bilateral critical area were used, the critical level of significance was 0.05. Statistical analysis of the research results was carried out in the statistical package EZR v. 1.54 (Saitama Medical Center, Jichi Medical University, Saitama, Japan, 2020) [10], which provide a graphical interface to R (The R Foundation for Statistical Computing, Vienna, Austria).

\section{Results}

The use of sodium dodecyl sulfate in the decellularization process can significantly affect the structure of the matrix collagen fibers $[11,12]$. Therefore, one of the main tasks was to conduct a study on the morphological assessment of the structure of matrix fibers that had already undergone the processes of decellularization and stabilization by the cross-linking method without glutaraldehyde. The use of a histological method makes it possible to assess the degree of matrix purification from cells and the degree of structural changes in collagen fibers. As a control, we used the native pericardium of cattle, in the form of a narrow plate with thick collagen and thin elastin fibers, and with densely formed connective tissue. In a sample of the native pericardium, a small amount of fusiform fibroblasts with rod-shaped, moderately basophilic nuclei and weakly basophilic cytoplasm were registered (Fig. 1, a). The structure of the collagen resembled tightly twisted bundles, which were located in a parallel direction to each other. This fiber architectonics provides pericardial resistance to mechanical stress.

In the Experimental technology for obtaining a decellularized extracellular matrix the effect of complete purification from cells and components was observed after 21 days of decellularization (Table 1). In the samples of this technology, the structure of the pericardium was similar to the native tissue. Collagen fibers were denser with no space between bundles. A decrease in the sinuosity of fibers inherent in native tissues was noted, and in some areas, on the contrary, the amplitude of fiber bending increased. The bundles resembled thick strands, between which spaces with thin fragmented fibers were locally formed (Fig. 1, C). 
Table 1.Histological analysis of cell detection in decellularized by various technologies matrix, hematoxylin-eosin staining method

\begin{tabular}{|c|c|c|c|c|c|}
\hline \multirow[t]{2}{*}{ Technologies } & \multicolumn{4}{|c|}{ Cells, $(\%)$} & \multirow[t]{2}{*}{$\mathrm{p}$} \\
\hline & $\begin{array}{l}\text { No cells in the } \\
\text { sample }\end{array}$ & $\begin{array}{l}\text { Single cells } \\
\text { in the sample }\end{array}$ & $\begin{array}{c}\text { A small } \\
\text { number of } \\
\text { cells }\end{array}$ & $\begin{array}{c}\text { A large number of } \\
\text { cells }\end{array}$ & \\
\hline $\begin{array}{c}\text { Control } \\
\text { (native bovine } \\
\text { pericardium) } \\
(\mathrm{n}=25)\end{array}$ & $\begin{array}{c}0 \\
(0,0)\end{array}$ & $\begin{array}{c}0 \\
(0,0)\end{array}$ & $\begin{array}{c}0 \\
(0,0)\end{array}$ & $\begin{array}{c}25 \\
(100,0)\end{array}$ & $<0,001$ \\
\hline $\begin{array}{c}\text { Experimental } \\
\text { Technology }(n=25)\end{array}$ & $\begin{array}{c}24 \\
(96,0)\end{array}$ & $\begin{array}{c}1 \\
(4,0)\end{array}$ & $\begin{array}{c}0 \\
(0,0)\end{array}$ & $\begin{array}{c}0 \\
(0,0)\end{array}$ & \\
\hline
\end{tabular}

Notes: the chi-square criterion was used for comparison between groups, posterior comparisons were made taking into account the Bonferroni correction.

The analysis revealed a statistically significant difference between the groups in terms of the parameter expression degree ( $\mathrm{p}<0.001$ according to the chi-square test). At the same time, the parameter expression degree for the Control group samples (cattle native pericardium) was statistically significantly $(\mathrm{p}<0.05)$ higher than for the samples of the Experimental Technology. It should be emphasized that for the Control group (native bovine pericardium) "no cells" was noted in $0 \%$ (95\% CI $0.0 \%-7.4 \%$ ) of samples, and for Experimental Technology - in 96.0\% (95\% CI 84.3\% - 100\%) samples.

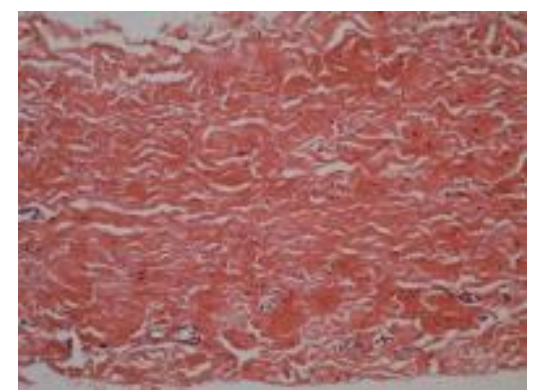

A

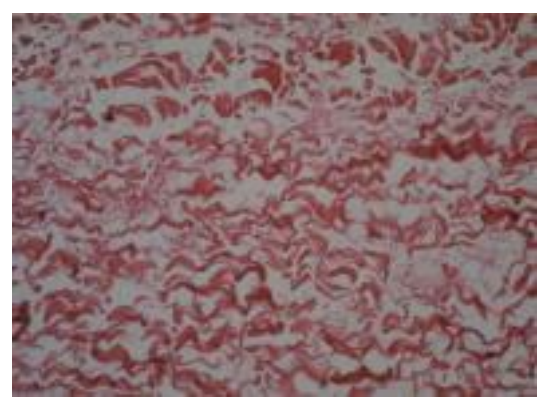

B

Fig. 1. Micrographs of histological sections of native and decellularized bovine pericardium; hematoxylin/eosin staining, light microscopy, x200. A - presence of visible violet cell nuclei, dense cords of collagen and elastin fibers (native bovine pericardium); B absence of visible cell nuclei in matrix, collagen and elastin fibers of lower density, but without structural changes (decellularized bovine pericardium by $0.1 \%$ SDS).

Qualitative microstructural analysis of SEM images also confirmed the absence of obvious changes in the structure and distribution between the collagen and elastin fibers of the decellularized extracellular matrix of the bovine pericardium (Fig. 2). The fibers are compactly arranged in relation to each other.

Also SEM showed that collagen fibers were reticulated in decellularized bovine pericardium after crosslinked by EDC/NHS and relative aperture of the collagen fiber was from 10 to $20 \mu \mathrm{m}$. 

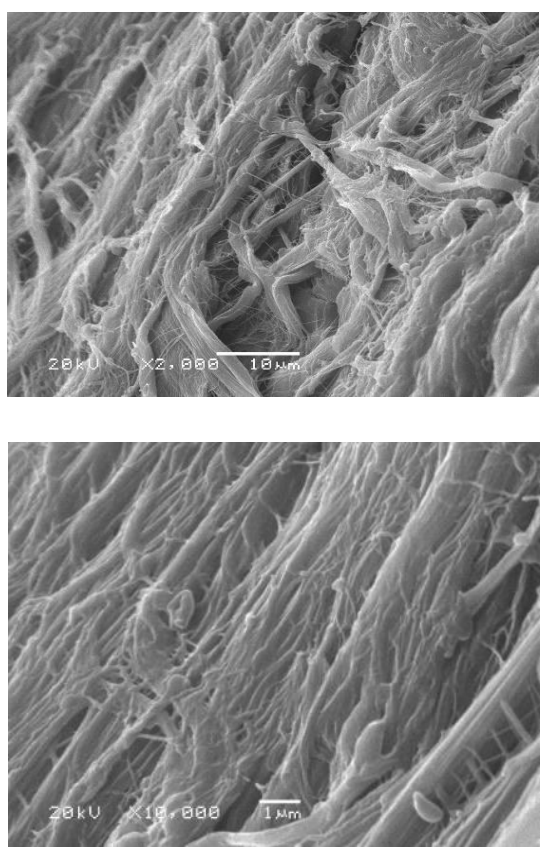
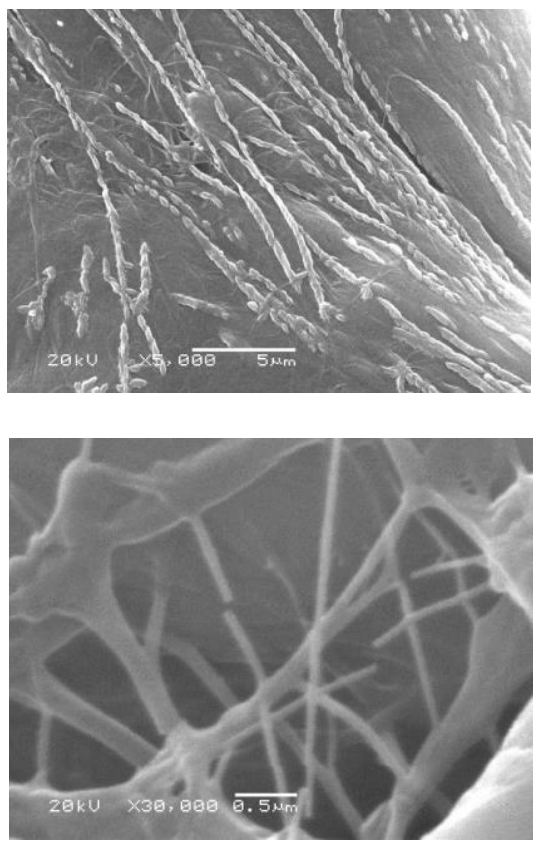

Fig. 2. Scanning electron micrographs of decellularized bovine pericardium ( $0.1 \%$ solution of SDS with EDC/NHS cross-linking)

\section{Discussion}

Decellularization is aimed at cleansing the collagen-elastin carcass from cells and their components. Such matrix can later be used as a cardiological patch to close defects of the cardiovascular tissue. It is important that the structure of the matrix would be as integral and strong as possible, due to the colonization with cells during biointegration into the donor tissue.

SDS is an effective decellularization agent and successfully applied in the decellularization of many tissues and whole organs [1-3]. However, many studies based on ECM ultrastructure report deleterious effects of SDS including reduction in collagen $[11,12]$. Alterations in the structural composition of ECM during decellularization can affect cell attachment, differentiation and function. Reduced cellular functionality have been attributed to matrix alterations caused by SDS decellularization [13]. However, low concentrations of SDS were shown to have less matrix disruption on kidney decellularization when little or no damage in renal tubules and vessels and minimal disruption of glomeruli were observed [14]. In our study, we used $0.1 \%$ SDS solution and no change in the microstructure of collagen-elastin fibers were found.

Usually after the process of decelularization the fiber structure is porous and stratified [6]. Therefore, an important step in tissue biotransformation is the final stage of stabilization. In the vast majority of commercial patches (scafolds) glutaraldehyde is used for fixation. However, residual glutaraldehyde can lead to cytotoxicity and calcification of the bioimplant with long-term observation [15]. In this study for the stabilizing the matrix fibers we used the soluble carbodiimide EDC (1-Ethyl-3- (3-dimethylaminopropyl) carbodiimide) and an organic substance derived from pyrrolidine NHS (N-hydroxysuccinimide), which are successfully used in medicine in the treatment of catarrh in vivo [16, 17]. EDC activates the carboxyl group in the amino acid by converting it to the intermediate isourea, which in turn binds to lysine residues or other available primary amines. Thus, an additional bond is formed between the two protein chains. To enhance the effectiveness of this carbodiimide, it is combined with NHS. NHS activates the carboxyl group, changing it to activated carboxylic acid ester, which reacts with amino groups to form an amide, forming a new bond between the chains. To stabilize the process of "crosslinking" the reaction is carried out in MES buffer. Microstructure analysis of SEM images in this study also confirmed that the micro-arhitectonic of the decellularized tissues by SDS and EDC/NHS cross-linking were not changed.

\section{Conclusion}

Histological and biomechanical data of the test showed that $0,1 \%$ SDS protocol is optimal for the procedure of decellularization of bovine pericardium. Studies have shown that pericardial tissue decellularized by low-concentration of 
$0.1 \%$ SDS saves the fiber architectonics and provides pericardial resistance to mechanical stress. The analysis revealed a statistically significant difference between the groups in terms of the parameter expression degree.

Thus, this study showed the effectiveness of using low concentrations of SDS (0.1\%) and EDC/NHS cross-linking in the decellularization.

\section{References}

[1] A.A. Sokol, D.A. Grekov, G.I. Yemets, A.Yu. Galkin, N.V. Shchotkina, A.A. Dovghaliuk, O.V. Telehuzova, N.M. Rudenko, O.M. Romaniuk, I.M. Yemets, "Comparison of bovine pericardium decellularization protocols for production of biomaterial for cardiac surgery", Biopolym. Cell., vol. 36, no 5, pp. 392-403, 2020.

[2] S.E. Gilpin, J.P. Guyette, G. Gonzalez, X. Ren, J.M. Asara, D.J. Mathisen, J.P. Vacanti, H.C. Ott, "Perfusion decellularization of human and porcine lungs: Bringing the matrix to clinical scale", The Journal of Heart and Lung Transplantation., vol. 33, no 3, pp. 298-308, 2014.

[3] A. Sokol, D. Grekov, G. Yemets, O. Galkin, N. Shchotkina, I. Yemets, "Biocompatiblibility analysis of the decellularized bovine pericardium", Cell and Organ Transplantology, vol. 8, no 2, pp. 112-116, 2020.

[4] E. Rieder, M.T. Kasimir, G. Silberhumer, G. Seebacher, E. Wolner, P. Simon, G. Weigel, "Decellularization protocols of porcine heart valves differ significantly in efficiency of cell removal and susceptibility of the matrix to recellularization with human vascular cells", J Thorac Cardiovasc Surg., vol. 127, no 2, pp. 399-405, 2004.

[5] A.A. Sokol, D.A. Grekov, G.I. Yemets, A.Yu. Galkin, N.V. Shchotkina, A.A. Dovghaliuk, N.M. Rudenko, I.M. Yemets, "The efficiency of decellularization of bovine pericardium by different concentrations of sodium dodecyl sulphate", Innovative Biosystems Bioengineering, vol. 4, no. 4, pp. 189-198, 2020.

[6] Xiu-Fang Xu1, Hai-Ping Guo, Xue-Jun Ren, Da Gong, Jin-Hui Ma, Ai-Ping Wang, Hai-Feng Shi, Yi Xin, Ying Wu, Wen-Bin Li1, "Effect of carbodiimide cross-linking of decellularized porcine pulmonary artery valvular leaflets", Int $J$ Clin Exp Med., vol. 7, no 3, pp. 649-656, 2014.

[7] V.G. Guryanov, Yu. E. Lyakh, V.D. Pariy, O.V. Korotky, O.V. Chaly, K.O. Chaly, J.V. Tcekhmister, Handbook of Biostatistics. Analysis of the results of medical research in the package EZR (R - statistics). Kyiv, Vistka, 2018.

[8] I.V. Nikolaenko, A.Iu. Galkin, G.E. Raevskaia, T.V. Kas'ianenko, M.I. Nereshchenko, E.S. Donskaia, N.Ia. Spivak, "Preparation of monoclonal antibodies to the Fc-fragment of human IgG and the use of their based immunoenzyme conjugates", Klin Lab Diagn., vol. 11, pp. 8-11, 2005.

[9] I.V. Nikolaenko, V.S. Goncharenko, N.N. Shimko, A.Yu. Galkin, "Isolation of surface antigen of hepatites B virus", Ukrain'skyi Biokhimichnyi Zhurnal, vol. 79, no 2, pp. 114-122, 2007.

[10] Y. Kanda, "Investigation of the freely available easy-to-use software 'EZR' for medical statistics.", Bone Marrow Transplant., vol. 48, pp. 452-458, 2013.

[11] D.M. Faulk, C.A. Carruthers, H.J. Warner, C.R. Kramer, J.E. Reing, L. Zhang, A. D’Amore, S.F. Badylak, “The effect of detergents on the basement membrane complex of a biologic scaffold material", Acta Biomater., vol. 10, no 1, pp. 183-193, 2014.

[12] H. Ren, X. Shi, L. Tao, J. Xiao, B. Han, Y. Zhang, X. Yuan, Y. Ding, "Evaluation of two decellularization methods in the development of a whole-organ decellularized rat liver scaffold", Liver international: official journal of the International Association for the Study of the Liver. vol. 33, no 3, pp. 448-458, 2013.

[13] O. Syed, N.J. Walters, R.M. Day, H.W. Kim, J.C. Knowles, "Evaluation of decellularization protocols for production of tubular small intestine submucosa scaffolds for use in oesophageal tissue engineering", Acta Biomater., vol. 10, no 11, pp. 5043-5054, 2014.

[14] M. Caralt, J.S. Uzarski, S. Iacob, K.P. Obergfell, N. Berg, B.M. Bijonowski, K.M. Kiefer, H.H. Ward, A. WandingerNess, W.M. Miller, Z.J. Zhang, M.M. Abecassis, J.A. Wertheim, "Optimization and Critical Evaluation of Decellularization Strategies to Develop Renal Extracellular Matrix Scaffolds as Biological Templates for Organ Engineering and Transplantation”, Am J Transplant., vol. 15, no. 1, pp. 64-75, 2015.

[15] H. Shang, S.M. Claessens, B. Tian, G.A. Wright, "Aldehyde reduction in a novel pericardial tissue reduces calcification using rabbit intramuscular model. Journal of materials science", Materials in medicine., vol. 28, no 1, pp. 1-16, 2017.

[16] G. Wollensak, E. Spoerl, T. Seiler, "Riboflavin/ultraviolet-a-induced collagen crosslinking for the treatment of keratoconus", Am J Ophthalmol., vol. 135, no 5, pp. 620-627, 2013.

[17] O.V. Shtapenko, I.I. Hevkan, Yu.I. Slyvchuk, V.Y. Syrvatka, N.M. Matvienko, "Formation and properties polymer nanolayers to enhance cell growth in vitro", Innovative Biosystems Bioengineering, vol. 2, no 2, pp. 105-109, 2018. 
ICBB 167-6 